\title{
REUMANIZANDO AS INVENÇÕES
}

Cristovam Buarque 


\section{A curiosidade inventa as invenções}

Por curiosidade, um dia um homem chocou duas pedras uma contra a outra e descobriu o ruído que isto fazia. Por este ato de curiosidade, o homem fez-se diferente dos demais animais. Ainda por pura curiosidade, outro homem bateu as pedras, e descobriu a faísca. Com os séculos, curioseando o som e a faísca, outro homem assustouse um dia ao ver que da faísca surgiu uma chama, em um capim seco que havia em frente.

Assim, pelo simples impulso de liberar a curiosidade, antes mesmo de ter consciência de si, o homem inventou a invenção.

\section{A invenção inventa o inventor}

Ao longo dos séculos, através de curiosear sobre o real, alguém teve consciência de si e dos seus gestos e de suas invenções. A invenção inventou então o inventor. $E$ o inventor humanizou-se.

No Ocidente, este processo atingiu o seu auge em dois momentos: no período 600 a.C. a 100 d.C., na Grécia e Roma, com o Classicismo; e na I tália, do século XIV ao século XVI, com o Renascimento. $O$ curioso evoluiu do choque das pedras ao violino; das marcas nas paredes das cavernas ao refinamento das formas e cores no teto da Capela Sixtina; da moldagem do interior de uma mão fechando-se sobre o barro à perfeição de uma Pietá ou de um Moisés; do fogo por acaso na palha às engenhocas de um aparelho para voar e à construção das catedrais; mas, sobretudo, da inocência da inconsciência à sofisticação socrática, tomista e maquiavélica, mantendo-se uma regra única ao longo de todo o processo: tudo inventado por simples curiosear sem qualquer propósito, além do prazer estético de inventar.

\section{3. $O$ inventor domina a invenção}

Pouco a pouco, porém, isto é rompido, na medida em que o inventor que se fez pelo ato de inventar começa a dominar a invenção e pô-la a seu serviço: nas máquinas, para sonhar guerras e nos instrumentos, para transformar a natureza.

$O$ inventor domina as invenções e o poder de inventar.

Ao longo dos últimos duzentos anos, este poder se acelerou e 
fez com que tudo fosse possível de ser transformado naquilo que o homem desejava obter.

A descoberta da faísca, provocando o fogo, transformou-se na capacidade de extrair fogo da própria entranha invisível da matéria. A curiosidade de observar e entender uma pedra rolando em um plano inclinado, levou à aventura de chegar à lua. Da montaria em animais inferiores, chegou-se à construção de sofisticados robôs. E o mundo, que era transformado em bens e serviços, fez dentro dele um sistema sócio-econômico que induzisse e exigisse um acelerado ritmo de produção de invenções.

A invenção deixou de ser o resultado e passou a ser dominada pelo propósito de transformar o mundo e criar riquezas. Do simples ato de curiosear, a invenção adquiriu um propósito utilitário, e exigiu uma organização produtiva para ela própria.

\section{A desumanização dos inventores}

O inventor moderno transformou-se em parte de uma máquina de produzir fins predeterminados por outros e para serem usados por outros. Para ser mais eficiente, para produzir na rapidez que o sistema exigia para criação de riquezas, o inventor assumiu metas sem questionar o propósito do que criava e deixou de usufruir da prática da curiosidade. A invenção, depois de dominada, passa a ter um papel exclusivamente utilitário ao sistema, sem gratificação existencial ao inventor, que não vê razão no ato de curiosear, mas sim no produto que obtém, nunca por escolha pessoal.

$O$ inventor foi dominado pela invenção.

\section{O fracasso das invenções}

Com extrema competência, o sistema usou inventores e produziu um novo auge. Com o produto da invenção por um mundo tecnocrático, eficiente no domínio do real, o sistema dos homens conseguiu realizar seus objetivos, atingindo um auge, equivalente, em termos de resultados, àquele dos gregos ou àquele dos florentinos. Mas as promessas não foram cumpridas. Apesar do inventor ter todo poder, as invenções não acabaram com a fome, e até a aumentaram; não resolveram o problema básico da sobrevivência da espécie e até amea- 
çaram conseguir em meia hora o que a natureza não o faria em milhões de anos.

\section{O despertar dos inventores}

Felizmente, porém, percebe-se o fracasso e o risco. As invenções começam a despertar os inventores. Inicia-se a observação dos resultados das invenções, formulam-se as perguntas do porquê e para quê; inicia-se a autocrítica dos inventores. As invenções despertam o inventor. E surge a necessidade de reumanizar as invenções e reinventar o homem.

Do outro lado, alguns inventores optam em manter-se fiéis ao propósito de curiosear, sem fim utilitário, sem um propósito produtivo, além do resultado que por acaso ocorra do ato de refletir filosoficamente, do gesto de pintar um quadro, do exercício de compor uma peça de música ou uma obra literária, da formulação ou solução de um teorema de matemática pura, do processo de reconstruir e recordar a história. É o homem que se dedica ao estudo das artes, das reflexões filosóficas, do humanismo; mas é um homem desumanizado também, porque restrito à sua especialidade, porque vive em um mundo moderno, mas às custas do trabalho dos outros, preocupado com o porquê das coisas do mundo, mas sem compromisso com estas coisas, nem com o mundo e suas circunstâncias.

\section{Reinvenção do humanismo}

Em excelente artigo publicado na Humanidades n.010, o dr. Sérgio Paulo Rouanet mostrou a necessidade de "reinventar as humanidades" retomando-se o ensino das disciplinas do humanismo, como forma de exercer contrapeso à difusão da cultura tecnocrática, de dar maior versatilidade ao espírito, de permitir o cultivo da crítica, "e, não menos importante" de utilizar as humanidades como fonte de prazer. Poucos pensamentos atuais têm a importância, a qualidade e a oportunidade do artigo do dr. Rouanet.

Mas a proposta do ensino das humanidades é ainda uma proposta tímida diante das exigências atuais, de ir além do ensino, em busca da criação de um novo pensamento que recrie os inventores. Mais do que reinventar as humanidades, nós necessitamos de uma reumanização das invenções do espírito humano. 


\section{0 repúdio às humanidades}

O que Rouanet observa no ensino brasileiro a partir do anos cinqüenta, com o repúdio ao bacharelismo e ao beletrismo como uma forma usada então para estar a favor do novo, é conseqüência direta do processo iniciado duzentos anos antes, com a Revolução Industrial e sua expansão em todo o mundo. Até um pouco antes, com John Webster, que em 1654 já propunha erradicar das universidades tudo o que considerava antigo e sem sentido. $O$ ensino das humanidades resistiu em parte pelo charme que exercem os estilos dos regimes anteriores sobre os novos regimes. Mas, em nenhum momento, o conhecimento das viagens de Ulisses ou o manuseio das declinações do Latim tinham sentido dentro da lógica da Revolução Industrial. Para este regime, muito mais importante do que as aventuras marítimas e filosóficas de Ulisses é a história do Billy, The Kid, ocupando o Oeste americano; mais sofisticado do que as declinações latinas são as simplificações do inglês básico comercial. E manter simultaneamente o ensino das humanidades e estudo dos aspectos da atualidade era um desperdício de tempo, era ineficiente na longa marcha do homem pela abundância, pela criação de um mundo livre do trabalho que a sociedade industrial oferecia. $O$ repúdio às humanidades não era, necessariamente, o repúdio ao humanismo, mas apenas o repúdio às recordações de um tipo de humanismo. Como dizia o próprio Webster, citado por $\mathrm{R}$. Nisbet, os gregos e romanos tinham orgulho e inteligência de empregar sua própria língua, e "nós, negligenciando a nossa, admiramos e empregamos a dos estrangeiros, o que é um hábito ridículo e prejudicial"

Não se tratava do fim das humanidades, e sim de uma nova humanidade representada posteriormente na "aculturação" do século XX. Mas aculturação medida pelos padrões do antigo regime, do saudosismo dos salões parisienses, onde o Classicismo resistia aos ataques do Romantismo, onde o próprio Balzac não era tolerado, porque falava do povo e do real, enquanto cultura era, então, falar do passado distante.

Com a crença no novo homem, que seria produto do desenvolvimentismo, não seria de estranhar as boas-vindas por quase todos, citadas por Rouanet, ao PIB, aos projetos, às taxas, ao futuro, em vez dos valores do passado. 
Seria de estranhar, talvez, o estrago que esta nova concepção de ensino, dirigida ao momento, compatível apenas com a época progressista, causou no espírito da sociedade brasileira.

\section{A reumanização das invenções}

Ao concentrar-se no moderno, no técnico, ao relegar ao passado as humanidades, nós não conseguimos atender os objetivos que foram prometidos. Desprezamos uma cultura que tinha um valór herdado do regime antigo, que já tinha, portanto, um valor e que oferecia um prazer, por uma nova cultura sem Dionísio, com um apelo cujo valor estava apenas no valor que seria criado na economia em vez das artes, no progresso em vez da hịtória, na força em vez da beleza, na velocidade em vez da contemplação. Mas as promessas não foram cumpridas. Bem ao contrário, o produto tornou-se o reverso do projetado: a fome expandiu-se, a miséria tomou conta das cidades construídas para a igualdade dos apartamentos, o desemprego cresceu mil vezes mais rapidamente do que as indústrias prometiam evitar.

E nós ficamos sem o novo e sem o velho, sem a infra-estrutura prometida e com uma superestrutura sem grande valor estético, sem Apolo e já sem Dionísio.

Daí a necessidade de reformulação da forma de objetivar o mundo, de representá-lo e de imaginar o seu futuro.

Mas não se trata apenas de retomar as humanidades. Trata-se de reformar o processo de criação. Já não se trata de reinventar as humanidades; a hora é de reumanizar as invenções.

\section{O caminho da reumanização}

Como deixa perceber Rouanet, a chave do processo de humanização está na educação. $O$ ensino das humanidades não é, porém, o único caminho para atender a reumanização dos inventores. Se não for complementado, o ensino das humanidades será apenas uma forma refinada de humanização, em que o intelectual aprende Latim, História da Grécia, e até História da Filosofia, na forma igualmente alienada dos inventores dominados pelo sistema. Mais grave ainda, a produção de conhecedores das humanidades pode ser uma forma do sistema social capitalista em crise viabilizar o seu funcionamento. As 
humanidades não teriam, assim, a função de fazer humanistas, mas sim de fazer um tipo de consumidor que obteria seu emprego graças ao ensino das humanidades que teriam por finalidade dinamizar a demanda através do emprego, em universidade, destes "humanólogos" E como se a proposta de Keynes de construir catedrais para empregar mão-de-obra, se aplicasse agora a empregar os conhecedores das catedrais góticas e das colunas gregas para que eles comprassem o que os outros fabricam.

O humanista rão pode ser visto como o homem que conhece as humanidades, este, no máximo, é humanólogo. O humanista deve ser o homem que tem conhecimento de suas circunstâncias, da sua responsabilidade diante delas e a modéstia de saber que não a conhece suficientemente; e que procura ampliar o horizonte deste conhecimento e desta responsabilidade, através da procura de entender suas origens e seu destino, e aprofundar suas relações circunstanciais com todo o universo.

E este sentimento de curiosidade pela globalidade e de responsabilidade diante do mundo que falta na grande maioria dos inventores modernos: sejam os que fabricam bombas, sejam os artistas, sejam os próprios conhecedores das humanidades. E é este sentimento que deve ser incorporado, como meta no ensino.

\section{Os vetores da reumanização}

Para isto, o ensino deve seguir quatro vetores.

O primeiro vetor consiste no que Rouanet propõe como ensino das humanidades. Através do ensino do passado, dos pensamentos e formas de pensar dos períodos clássicos, da descoberta dos valores da estética, o homem torna-se um pouco mais humanista, ao adquirir consciência de sua origem. Muito especialmente será necessário incentivar e promover o ensino e a prática das reflexões filosóficas, do gasto da atividade artística e, também, do desafio esportivo.

$O$ segundo vetor é o ensino da consciência da natureza. $O$ êxito da eficácia das técnicas, a partir do século $X \mid X$, desmentindo os mitos malthusianos, gerou um sentimento de onipotência de parte dos modernos homens de saber. Ao mesmo tempo que isto estimula o sentimento de um chauvinismo humanista, no sentido de superioridade da espécie, enfraquece e ameaça a consciência humanística. En- 
fraquece, porque o homem, ao desprezar a natureza, esquece que ele é apenas parte dela, ainda que a mais importante a seus olhos. Ameaça, porque, ao desprezar a natureza, o homem começa a criar subsistemas descontrolados, no complexo ecológico do qual depende sua vida.

O terceiro vetor é a descoberta de si próprio, como indivíduo. Pode parecer contraditório que a descoberta da humanidade, o rompimento do egoísmo, deva passar pela redescoberta do indivíduo. Mas, este talvez seja o ponto-chave da humanização das invenções: a descoberta do inventor pelo inventor, como forma de ele romper com a alienação de seu trabalho, de optar por uma função que se justifique por sua própria prática e não pelo resultado, e assim, ao desalienar-se, desalienar a invenção, humanizando-a, através de si próprio. Atualmente, isto não ocorre, os inventores não vivem experiências, eles as fazem, alienadamente, não curioseiam, não sentem suas invenções, não as praticam por prazer: exercem uma função em uma extensa cadeia produtiva, com a meta de produzir a invenção que o sistema deseja, e ganhar para si um salário, um título e, até, um prêmio Nobel. Mas, raramente, pela simples e pura razão humana de curiosidade. É daí que vem a imagem do cientista amargado, dedicado apenas ao seu ofício, desconhecendo que gasta no trabalho a sua única vida. O cientista que redescubra a unicidade de sua vida, que procure tirar o prazer de viver que ela lhe oferece, certamente caminhará para uma convivência mais saudável com os seus circunstantes, e, portanto, com suas circunstâncias, humanizando-se.

Finalmente, o quarto vetor -é a política. Só através da prática política o homem adquire consciência e pratica suas responsabilidades com suas circunstâncias. A prática da política não se restringe ao conceito de militância partidária, mas sim ao conceito de engajamento no processo de decisões que conduz o rumo e o uso das invenções. Mesmo no período greco-romano ou no Renascimento, o humanismo exigia a consciência e a prática política. A partir de meados do século $X X$, esta exigência torna-se uma absoluta necessidade, em função de três fatores: primeiro, o fato de que o inventor não produz isoladamente, e portanto, não escolhe, ele sozinho, qual será sua invenção, devendo portanto se não quiser ser apenas um robô, participar das decisões; segundo, porque as invenções passam a ter conse- 
qüências dramáticas para a sociedade e até para toda a humanidade, fazendo com que a produção do saber passe a ser uma irresponsabilidade social, incompatível com o humanismo; terceiro, porque o crescimento da sofisticação do processo social faz com que o saber legitime cada vez mais o acesso ao poder, e se os inventores não participarem politicamente, serão coniventes com uma tendência à tecnocratização das estruturas governamentais, e responsáveis por todos os efeitos perversos que disto decorre. Dois exemplos ilustram bem isto: a construção e uso da bomba e da energia nuclear e a complexidade do processo econômico. Os físicos nucleares e os economistas, como inventores, alienando-se do processo político e limitando-se a robôs-processadores de invenções, estarão rompendo seus laços com as suas circunstâncias e oferecendo de forma irresponsável um saber de dramática força e efeito.

\section{A invenção dos inventores humanistas}

Se o ensino das humanidades não é suficiente no processo de humanização do inventor, é, entretanto, na educação que está a chave do processo de re-humanização. A formação de um humanista deve começar com o ponto de partida da formação do homem e sua maior invenção: a linguagem. Deve, portanto, iniciar-se no berço. A sociedade deve perceber que não pode desperdiçar, em sua formação, a formação de cada indivíduo, desde sua infância. A sociabilidade e o brinquedo, primeiras manifestações de humanismos, devem ter um caráter humanista. A escola, desde seu início, deve incentivar a igualdade entre raças, sexos e povos, deve evitar qualquer incentivo à violência e à guerra; deve promover o espírito crítico, a procura da verdade, o entendimento do homem e o entendimento entre os homens; a formação global, a sensibilidade estética, tanto quanto a curiosidade técnica e científica.

Mas, é na Universidade que se encontra o principal centro formador do produtor intelectual e que deve ser estruturado de forma a produzir o inventor humanista. Para isto, quatro linhas básicas de mudanças devem ser cumpridas na Universidade:

a) Primeiro, o rompimento da estrutura arcaica da divisão apenas conforme as categorias científicas. A Universidade baseada exclusivamente em departamentos prende cada porissional, desde a sua 
formação, em um claustro que impede a visão de globalidade, que dificulta o entendimento das circunstâncias, nas quais o inventor se insere, dificultando ao máximo sua formação humanista. A solução deste aspecto consiste em dois caminhos: de um lado, a continuação da organização universitária nos departamentos que organizam o conhecimento de uma maneira mais eficaz, ao mesmo tempo em que se estruturam núcleos interdisciplinares, em torno do estudo de temas, de problemas, e não de categorias científicas; de outro lado, a permeabilidade de todos os universitários, de todas as categorias, por assuntos que digam respeito à formação e a prática das humanidades, tais como filosofia, artes, esportes, história, promovidos através de pólos de promoção destas atividades.

O ensino se daria, assim, através de três eixos: a especialidade profissional em um setor do conhecimento humano, em um Departamento; a orientação aos problemas da sociedade e da natureza ou mesmo do conhecimento puro, mas procurando respostas complexas e globais através de um trabalho integrado interdisciplinarmente, entre os especialistas do entendimento do problema e os estudiosos de suas circunstâncias; e a complementação pela formação humanística, no estudo e na prática das reflexões filosóficas, das artes; da bistória.

b) Segundo, o ensino deve ser crítico. O humanismo exige o curiosear, que requer a dúvida, a crítica a todo pensamento. As invenções só ocorrem através da contestação teórica. $O$ ensino, portanto, deve romper em vez de promover as marcas do conhecimento tradicional. Em vez de transmissora de conhecimento, a Universidade deve ser criadora de conhecimento, e isto exige a prática da dúvida, o respeito, sem preconceitos, a todas as vertentes de idéias, novas ou velhas; e ao mesmo tempo a insubmissão e subversão a todas as idéias.

c) Terceiro, a Universidade deve abrir-se ao mundo exterior, como forma de entendê-lo e de envolver-se em suas circunstâncias.-Para isto é preciso desenvolver programas de extensão, atrair pessoas do Exterior à Universidade, promover cursos por meios não-tradiciopais, como jornais, vídeos e outros.

d) Quarto, a Universidade deve ser um ambiente extremamente democrático, como forma de induzir a prática da critica e da política. Sem este aniente, tornam-se impossiveis todas as outras 
práticas, o conhecimento das circunstâncias, a participação nos destinos de todos os homens, a condução humanista das invenções.

\section{As invenções redominadas}

O homem percorreu um longo caminho, do chocar pedras por curiosidade à construção do sofisticado sistema de vida que cobre o planeta, graças às invenções de seu cérebro. Neste processo, o homem humanizou-se e desumanizou-se, o homem construiu, destruiu e ameaça hoje o planeta e a si.

A crise, porém, o fim das promessas, leva a um resurgimento da consciência crítica e à descoberta da necessidade de uma reumanização. Mas não há caminho de volta à inocência da curiosidade pura.

Agora é hora de reumanizar-se pela prática da vida, pela desrobotização, através da consciência e militância nas circunstâncias que rodeiam cada um de nós, por meio do conhecimento de nossas origens e da imaginação de nosso destino. É nisto que consiste e é para isto que precisamos tentar a Reumanização dos Inventores.

Este artigo foi elaborado como parte dos debates realizados no Núcleo de Estudos Brasil, da UnB, em torno ao provocativo artigo do dr. Sérgio Paulo Rouanet - "Reinventando as Humanidades", publicado na.Revista Humanidades n? 10 - ago./out. - 1986.

Fizeram parte dos debates os seguintes componentes do Núcleo: Sérgio Paulo Rouanet, Mauro Santayana, Geraldo Morais, José Geraldo Souza, Elizabeth Cataldo, Austragésilo Spíndola, Luís Tarley Aragão, Milton Cabral, Nielsen de Paula Pires, Ivônio Barros Nunes, Flávio Sombra Saraiva. 
FICHA CATALOGRAFICA

BUARQUE, Cristovam. Reumanizando as Invenções. Ro vista da Universidade de São Paulo. São Paulo, (4): p. 75 - 86, março de 1987. 